\title{
Japan election sparks science pledges
}

\section{Both parties make vague promises about research, but differ in their climate targets.}

Japan's upcoming elections, on 30 August, could see the party that has ruled almost continuously for more than half a century lose its grip on power. As Nature went to press, polls suggested that the Democratic Party of Japan (DPJ) would take a majority in the lower house of parliament, giving it the right to appoint a prime minister to replace Taro Aso of the Liberal Democratic Party (LDP).

Some researchers have expressed concern that the DPJ, with its emphasis on the responsible use of taxes, might cut basic-research budgets. Last week at a press conference, DPJ president Yukio Hatoyama tried to dispel such rumours. "Japan should be a leading country in basic science," he said in response to a question from Nature. "If anything, I think overall scientific funding should be expanded."

The DPJ has been throwing out similar promises to voters concerned about Japan's struggling economy. For example, the party's manifesto includes a new annual allowance of $¥ 312,000$ (US\$3,300) for every child until they finish junior high school. The party says that it can pay for this and other big programmes by reducing spending elsewhere, such as on road and dam projects, and shifting decision-making power towards elected officials and away from government bureaucrats.

But Japan last week officially pulled out of recession, and many scientists have been happy with the way bureaucrats have fought to maintain or even increase the science budget during slow economic growth (see chart) when most other sectors of government were seeing budgets cut. Major projects include the Japan Proton Accelerator Research Complex in Tokaimura and the X-ray free-electron laser scheduled to be completed next year at the

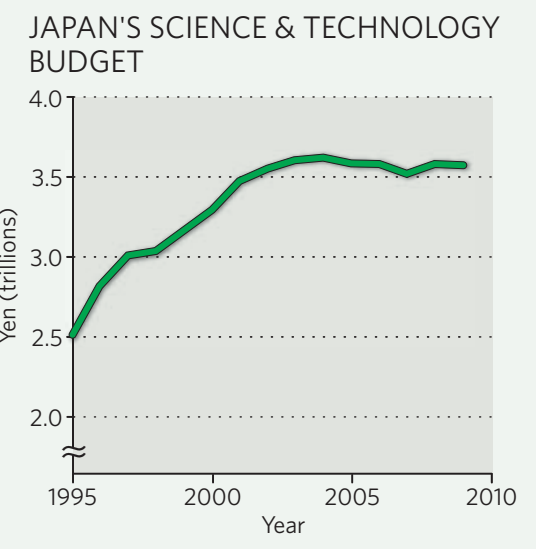

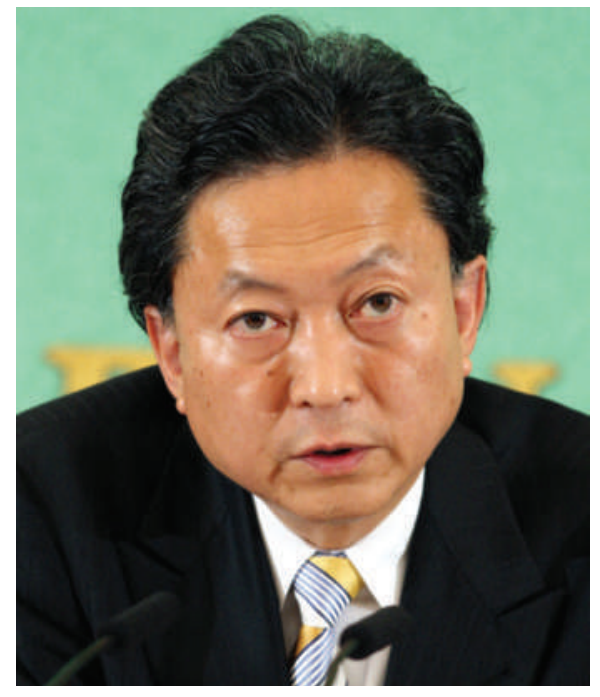

Yukio Hatoyama, president of the opposition DPJ.

SPring-8 synchrotron in western Japan.

Biophysicist Akiyoshi Wada, former director of RIKEN's Genomic Sciences Center in Yokohama, speculates that the DPJ's declared drive to get rid of waste might affect research. "They say they want to stop listening to the bureaucrats, but how much will they be able to do without?" Wada asks. "Large-scale 'challenging' projects might get drastically cut." Indeed, the party's manifesto promises to re-evaluate the "independent administrative organizations" that include many of Japan's largest research bodies, among them RIKEN.

In response to a Nature questionnaire, Hatoyama's office pledged support for big projects: "Japan is already a top runner in some fields that require huge budgets, like particle physics," it said, "and we will actively aim to maintain that position by building world-class research bases and deepening research ties with Europe, the United States and Asian countries." The statement also said that the DPJ would take (unspecified) measures to increase the science budget. It noted that although Japan overall invests a high percentage of its gross domestic product (GDP) in research - 3.67\% in 2007 - the percentage of government investment is low compared with investment by industry. "Cultivating researchers needs to be part of our central policies," the statement said.

Hatoyama received a doctorate in engineering from Stanford University in California and was a professor at the Tokyo Institute of Technology. He plays down his scientific background, saying "what matters for politicians is having principles and convictions, and a broad perspective". Naoto Kan, the former DPJ head and one of its two acting presidents, got a doctorate in applied physics before becoming a patent lawyer; some say he might bring more attention to issues that have plagued Japanese patent law, such as the need for broader patents to compete with the United States and streamlining the lengthy patent application procedure.

Hatoyama says that the DPJ will create a 'science and technology strategy office' to replace the Council for Science and Technology Policy (CSTP), the country's highest science-policy body. Like the CSTP, the new office would coordinate science-related budget requests, but it would also, in ways unspecified, take a more active role in "promoting basic and applied sciences in a unified manner".

If the DPJ does create a top-level scientific body, this might find itself in the thick of an ongoing debate over the role of big science projects. Tadamitsu Kishimoto, an immunologist at Osaka University and a former CSTP member, says money has been wasted on big biology projects, and he complains that the $¥ 270$ billion earmarked for 30 new projects by the CSTP could be more of the same. "Right now young PIs don't get enough to work with," he says, "and using that money to give $¥ 10$-million grants to many young researchers would produce a lot more good science."

The LDP platform acknowledges the many Nobel prizes garnered by Japanese scientists, and vows to "educate and send out into the world more researchers than ever before", and to create 30 "world-class research facilities".

On climate change, the DPJ calls for a cut in greenhouse-gas emissions to more than 25\% below 1990 levels by 2020 . The LDP's proposal of an $8 \%$ target has been criticized by developing countries and environmental groups as not going far enough. But Japan has consistently missed targets for its original Kyoto Protocol pledge to cut emissions to 6\% below 1990 levels during 2008-12, and many in the business community in particular are sceptical about the DPJ's emissions targets.

"If we follow the DPJ's targets, we will end up with a $3.2 \%$ drop in the GDP" based on government estimates, LDP secretary-general Hiroyuki Hosoda said last week. "The party that presents the more dramatic figure is more attractive, but it is not feasible," he said.

David Cyranoski 